CORKILL, L. 1952. Cyanogenesis in white clover (Trifolium repens L.). VI. Experiments with high glucoside and glucoside free strains. $\mathcal{N}$.Z. F. Sci. Tech., 34A, 1-16.

DADAY, H. 1954. Gene frequencies in wild populations of Trifolium repens L. 1. Distribution by latitude. Heredity, $8,61-78$.

DADAY, H. 1955. Cyanogenesis in strains of white clover (Trifolium repens L.). F. Brit. Grassland Soc., 10, 266-274.

DADAY, H. 1965. Gene frequencies in wild populations of Trifolitm repens L. IV. Mechanism of natural selection. Heredity, 20, 355-365.

DAWson, G. D. R. 1941. Tetrasomic inheritance in Lotus corniculatus L. F. Genetics, 42, 49-72. HUGHES, M. A. 1968. Studies on the $\beta$-glucosidase system of Trifolizm repens L. F. Exp. Bot., $19,427-434$

JONEs, D. A. 1966. On the polymorphism of cyanogenesis in Lotus corniculatus L. Selection by animals. Canad. 7. Genet. Cytol., 8, 556-567.

JONEs, D. A. 1968. On the polymorphism of cyanogenesis in Lotus corniculatus L. II. The interaction with Trifolium repens L. Heredity, 23, 453-455.

SNEDECOR, G. W., AND COCHRAN, W. G. 1967. Statistical Methods. 6th Edition, Iowa State University Press, Ames.

\title{
LIGHT AND TEMPERATURE EFFECTS ON THE GERMINATION OF WILD OATS
}

\author{
W. J. WHITTINGTON, J. HILLMAN, S. M. GATENBY, B. E. HOOPER \\ and J. C. WHITE \\ University of Nottingham School of Agriculture, Sutton Bonington, \\ Loughborough, Leicestershire
}

Received 6.v.70

\section{INTRODUCTION}

Avena fatua L. and Avena ludoviciana Dur. are the wild oats of English agriculture. $A$. ludoviciana tends to occur on heavy land where winter cereals are grown, and the caryopses (seed or grain) of this species germinate mainly in autumn. $A$. fatua, on the other hand, has a wider distribution and is particularly associated with spring cereals (Thurston, 1954); the grain of this species show some germination in autumn but a considerably greater frequency of germination occurs in spring (Thurston, 1951). Reports indicate considerable variation in the degree and periodicity of dormancy both between and within samples of $A$. fatua from different localities (Toole and Coffman, 1940; Sexsmith, 1967).

The genetic control of dormancy in oats has been considered by Garber and Quisenberry (1923), who found that delayed germination was recessive in crosses involving $A$. fatua and A. sativa. Johnson (1935b), using similar material, suggested that the observed variation could be explained on a three-locus basis in which the triple recessive genotype showed greatest dormancy.

Purely genetic models invoked to explain germination characteristics ignore the very marked effects of environmental factors during grain development. Thus, both the position in the spikelet at which the seed develops and the storage conditions markedly affect germination behaviour (Johnson, 1935a; Kommedahl, DeVay and Christensen, 1958; Thurston, 1963a). Environmental effects also cause variation during germination (Black and Naylor, 1957). Gumming and Hay (1958) found an inhibitory effect of 
white light on partially dormant grain but no effect on non-dormant seed. Thurston (1964) reported photoperiodic effects in both $A$. fatua and $A$. ludoviciana, with short days being more favourable to germination than long days.

The optimum temperature for the retention of viability and loss of dormancy was reported as being in the range of $7^{\circ}-14^{\circ} \mathrm{C}$. for both species (Thurston, 1963b). A later report, however, suggested that lower temperatures favoured dormancy in $A$. fatua and higher temperatures dormancy of $A$. ludoviciana (Thurston, 1966). Friesen and Shebeski (1961) obtained the best and most rapid germination of $A$. fatua at $21^{\circ} \mathrm{G}$.

Germination is not only affected by the environment since pricking and removal of the husk is also known to remove dormancy and promote germination (Johnson, 1935a; Black, 1959; Hart and Berrie, 1966).

In this paper an analysis is made of the germination characteristics in a range of environments of $A$. fatua, A. ludoviciana and a number of hybrid families derived from intercrossing these species.

\section{Materials and methods}

The families used in these experiments were derived by selfing and intercrossing one plant each of Avena fatua and Avena ludoviciana. The $\mathrm{F}_{1}$ and $\mathrm{F}_{2}$ generations were grown and seeds were obtained of $48 \mathrm{~F}_{8}$ hybrid families. The parental lines were maintained by selfing. Twelve families (1-12) showed the $A$. fatua type of caryopsis articulation in which the caryopses in the spikelet easily separate from each other. The remaining 36 families (13-48) showed the $A$. ludoviciana type of caryopsis articulation whereby the grains separate only by direct fracture of the rachilla. This character was determined by the $F_{2}$ parent plants and the observed result was in agreement with the $3: 1$ ratio expected.

In Experiment 1, five of the lowest seeds in the spikelet, enclosed by lemma and palea (husk) from the two parents and $48 \mathrm{~F}_{3}$ families, were planted in $90-\mathrm{mm}$. pots containing compost. There were two replicates of each genotype and the pots were arranged in a lighted growth cabinet at $10^{\circ} \mathrm{C}$. The numbers of emerged seedlings were recorded after 21 days. One plant of each line was later removed to the greenhouse in order to maintain the lines into the $\mathrm{F}_{4}$ generation. Four weeks after emergence the experiment was repeated (Experiment 2).

In Experiment 3 the germination characters of the parents and 40 of the $F_{4}$ families were examined. Because insufficient grain was available lines $5,9-11,18,28,35$ and 36 , used previously, were omitted. The seed used in this experiment had been stored in the laboratory for three months. Germination tests were carried out on Whatman No. 1 filter paper in $90-\mathrm{mm}$. plastic petri dishes, using five seeds in each dish. There were two replicates of each family, both with and without husks, under each of two temperatures $\left(5^{\circ} \mathrm{C}\right.$. and $18^{\circ} \mathrm{C}$. $)$ and three light regimes $(0,8$ and 18 hours photoperiod in 24-hour cycles). The experiments were carried out in two growthrooms. Examination of the seeds in the dark treatment was conducted in dim green light.

Finally, in Experiment 4, the effects of darkness on germination at $5^{\circ} \mathrm{C}$. were examined by placing seeds of the parents and $40 \mathrm{~F}_{5}$ families on moistened filter paper three months after harvest. There were five replicate petri 
dishes each with five grains and lines $9,10,11,13,14,28,35,36$ were excluded because insufficient seed was available.

\section{RESULTS}

In Experiment 1 there were highly significant differences between families in the number of seeds which had germinated, i.e. whose seedlings had emerged above ground by 21 days (V.R. 2.82** for 49 Degrees of Freedom). The mean numbers of germinated seeds of hybrids with $A$. fatua type articulation were not significantly different from those from $A$. ludoviciana type hybrids. The germination percentage of $A$. ludoviciana itself was higher than that of $A$. fatua, while only two families (14 and 36) out of 48 showed low numbers of emerged seedlings (table 1). The values recorded in Experiment 2 were higher but the regression coefficient for the results of Experiment 1 on Experiment 2 was significant $(b=0.72 \pm 0.11)$.

\section{TABLE 1}

Percentage germination of the 50 families after 22 days (S.E. $\pm 5 \cdot 9$ )

\begin{tabular}{crrrrrrrrr} 
Species or line & \multicolumn{1}{c}{$\%$} & Line & \multicolumn{1}{c}{$\%$} & Line & \multicolumn{1}{c}{$\%$} & Line & $\%$ & Line & $\%$ \\
A. fatua & 40 & 9 & 100 & 19 & 100 & 29 & 80 & 39 & 70 \\
$\begin{array}{c}\text { A. ludoviciana } \\
\text { Line }\end{array}$ & 70 & 10 & 60 & 20 & 100 & 30 & 100 & 40 & 100 \\
2 & 90 & 11 & 10 & 21 & 100 & 31 & 90 & 41 & 90 \\
3 & 80 & 12 & 90 & 22 & 90 & 32 & 90 & 42 & 80 \\
4 & 80 & 13 & 100 & 23 & 100 & 33 & 80 & 43 & 60 \\
5 & 100 & 14 & 50 & 24 & 100 & 34 & 80 & 44 & 70 \\
6 & 90 & 15 & 100 & 25 & 90 & 35 & 100 & 45 & 60 \\
7 & 100 & 16 & 100 & 26 & 80 & 36 & 30 & 46 & 60 \\
8 & 70 & 17 & 80 & 27 & 90 & 37 & 90 & 47 & 90 \\
& 70 & 18 & 80 & 28 & 90 & 38 & 80 & 48 & 60
\end{tabular}

Statistical analyses of the results after 18 days for Experiment 3 after transformation into angles (Fisher and Yates, 1963) showed that the main effects of Temperatures, Light, Husk and Genotypes were significant. The Genotypes showed significant interactions with the effects of Husks, Light and Temperature (table 2). The origin of these effects is most clearly seen, however, by examination of untransformed values omitting the results from the 8-hour light treatment which were similar to those in the 18-hour photoperiod. The number of germinated seeds was highest at $5^{\circ} \mathrm{C}$. in the light with the husks removed (table 3 ). The relatively good germination of family 8 in this environment contrasted with its performance in other treatments and indicated that low or zero germination did not reflect seed viability.

Consideration of the results for the parents showed that seeds of $A$. ludoviciana, unlike $A$. fatua, were inhibited in the light at $18^{\circ} \mathrm{C}$. and are apparently highly temperature sensitive. Light was required by $A$. fatua in the presence of the husk to enable good germination at $18^{\circ} \mathrm{C}$. Exposure to light did not improve the germination of $A$. ludoviciana at this temperature. At $5^{\circ}$ C. $A$. fatua showed low germination unless the seeds were exposed to light or the husks removed. The germination of seeds of $A$. fatua is clearly modified by the presence of the husk whose inhibitory effects can be alleviated by removal or by illumination.

The hybrid families exhibited a considerable range of variation, some 
lines showing good germination in all environments, e.g. 25 and 30, whereas others germinated better at low temperatures, e.g. family 19. Some families only germinated at $5^{\circ} \mathrm{C}$. in the absence of their husks, e.g. 8 and 47 .

At $5^{\circ} \mathrm{C}$. the lowest germination was recorded for seeds with husks in the dark, but, as would be expected, the removal of the husk or exposure to light increased the total number of hybrid line seeds which had germinated. A frequency distribution for the numbers of seeds which had germinated in each family at $5^{\circ} \mathrm{C}$. in the dark with the husks retained showed some evidence of a bimodal distribution (fig. $1 a$ ). At $18^{\circ} \mathrm{C}$. the same germination pattern was obtained with the different families in that germination was worst in

TABLE 2

Analysis of variance of the effects of varying temperatures, husking treatments and photoperiods on the germination of A. fatua, A. ludoviciana and $40 \mathrm{~F} 4$ hybrid families. Percentage germination was transformed to angles for analysis

\begin{tabular}{|c|c|c|c|}
\hline Item & d.f. & M.S. & V.R. \\
\hline Temperature & 1 & $55860 \cdot 4$ & $535 \cdot 52 * * *$ \\
\hline Light & 2 & $4941 \cdot 9$ & $47 \cdot 37 * * *$ \\
\hline Genotype & 41 & $1669 \cdot 3$ & $16 \cdot 00 * * *$ \\
\hline Husk & 1 & $13849 \cdot 6$ & $132 \cdot 80^{* * *}$ \\
\hline Temperature $\times$ Light & 2 & $249 \cdot 1$ & N.S. \\
\hline Temperature $\times$ Genotype & 41 & $525 \cdot 4$ & $5 \cdot 03 * * *$ \\
\hline Temperature $\times$ Husk & 1 & $52 \cdot 3$ & N.S. \\
\hline Light $\times$ Genotype & 82 & $144 \cdot 6$ & $1 \cdot 38 * * *$ \\
\hline Light $\times$ Husk & 2 & $1502 \cdot 4$ & $14 \cdot 40 * * *$ \\
\hline Genotype $\times$ Husk & 41 & $255 \cdot 3$ & $2 \cdot 44 * * *$ \\
\hline Temperature $\times$ Light $\times$ Genotype & 82 & $80 \cdot 9$ & N.S. \\
\hline Temperature $\times$ Husk $\times$ Genotype & 41 & $189 \cdot 6$ & $1 \cdot 81 * * *$ \\
\hline Temperature $\times$ Husk $\times$ Light & 2 & $159 \cdot 8$ & N.S. \\
\hline Light $\times$ Genotype $\times$ Husk & 82 & 99.9 & N.S. \\
\hline Error & 82 & $104 \cdot 3$ & \\
\hline
\end{tabular}

the dark for seeds with husks, but was improved by either removing the husks or supplying light. Examination of the frequency distribution for seeds with husks in the light showed some evidence of bimodality (fig. $1 b$ ).

In Experiment 4, seeds from each newly grown parental line and the $F_{5}$ generation of 40 of the families were germinated in the dark at $5^{\circ} \mathrm{C}$. with the husks retained. The results after 26 days confirmed that $A$. fatua germinated poorly in this environment ( 2 seeds out of 25 ) whereas seed of A. ludoviciana germinated well (18 out of 25 seeds). Certain families germinated badly ( 47 and 26) or well (37 and 30) in both Experiments 3 and 4, but there was considerable variation between these experiments in the numbers of each genotype which had germinated.

\section{Discussion}

In these experiments later generations than the $\mathrm{F}_{2}$ were analysed because maternal and maternal interaction effects, which cause difficulty in studies on the genetic control of germination (Harper and McNaughton, 1960; Battle and Whittington, 1969a, b, 1970), are reduced. The experimental results showed clearly that the germination characteristics of the chosen 
TABLE 3

Numbers of seeds out of ten of $\mathrm{A}$. fatua, A. ludoviciana and 40 families which germinated at $5^{\circ} \mathrm{C}$. or $18^{\circ} \mathrm{C}$., in darkness or with exposure to 18 hours photoperiod and with $(+)$ or without $(-)$ husks

\begin{tabular}{|c|c|c|c|c|c|c|c|c|}
\hline \multirow[b]{3}{*}{$\begin{array}{l}\text { Species } \\
\text { or line }\end{array}$} & \multicolumn{4}{|c|}{$5^{\circ} \mathrm{C}}$. & \multicolumn{4}{|c|}{$18^{\circ} \mathrm{C}$. } \\
\hline & \multicolumn{2}{|c|}{ Light } & \multicolumn{2}{|c|}{ Dark } & \multicolumn{2}{|c|}{ Light } & \multicolumn{2}{|c|}{ Dark } \\
\hline & + & - & + & - & + & - & + & - \\
\hline A.f. & 6 & 8 & 1 & 6 & 7 & 8 & 0 & 4 \\
\hline A.1. & 9 & 5 & 8 & 7 & 0 & 0 & 1 & 4 \\
\hline 1 & 10 & 5 & 10 & 9 & 8 & 5 & 3 & 6 \\
\hline 2 & 9 & 10 & 8 & 7 & 1 & 6 & 1 & 2 \\
\hline 3 & 5 & 6 & 4 & 9 & 7 & 8 & 0 & 6 \\
\hline 4 & 9 & 8 & 4 & 9 & 5 & 7 & 4 & 6 \\
\hline 6 & 5 & 9 & 5 & 8 & 4 & 8 & 0 & 3 \\
\hline 7 & 7 & 5 & 0 & 5 & 1 & 5 & 0 & 1 \\
\hline 8 & 1 & 10 & 0 & 5 & 0 & 1 & 0 & 0 \\
\hline 12 & 10 & 9 & 10 & 9 & 5 & 7 & 3 & 9 \\
\hline 13 & 8 & 9 & 8 & 10 & 9 & 9 & 2 & 7 \\
\hline 14 & 4 & 8 & 1 & 5 & 1 & 4 & 0 & 2 \\
\hline 15 & 9 & 10 & 5 & 10 & 6 & 10 & 4 & 8 \\
\hline 16 & 8 & 6 & 6 & 6 & 9 & 7 & 3 & 9 \\
\hline 17 & 9 & 9 & 5 & 9 & 6 & 3 & 0 & 6 \\
\hline 19 & 7 & 9 & 6 & 9 & 2 & 0 & 0 & 1 \\
\hline 20 & 9 & 8 & 10 & 10 & 6 & 8 & 8 & 8 \\
\hline 21 & 10 & 9 & 10 & 9 & 6 & 5 & 5 & 7 \\
\hline 22 & 4 & 8 & 1 & 7 & 5 & 5 & 1 & 3 \\
\hline 23 & 10 & 10 & 6 & 10 & 5 & 5 & 3 & 6 \\
\hline 24 & 9 & 10 & 6 & 9 & 6 & 8 & 1 & 7 \\
\hline 25 & 8 & 6 & 9 & 9 & 10 & 10 & 8 & 9 \\
\hline 26 & 2 & 6 & 2 & 7 & 2 & 4 & 0 & 2 \\
\hline 27 & 8 & 10 & 0 & 7 & $\overrightarrow{1}$ & 4 & 0 & 1 \\
\hline 29 & 6 & 9 & 6 & 7 & 1 & 5 & 0 & 2 \\
\hline 30 & 10 & 10 & 8 & 10 & 8 & 10 & 7 & 9 \\
\hline 31 & 8 & 10 & 6 & 9 & 9 & 10 & 5 & 9 \\
\hline 32 & 5 & 7 & 8 & 10 & 2 & 6 & 2 & 7 \\
\hline 33 & 8 & 7 & 9 & 8 & 5 & 3 & 1 & 3 \\
\hline 34 & 9 & 6 & 8 & 9 & 5 & 0 & 2 & 6 \\
\hline 37 & 10 & 8 & 10 & 5 & 7 & 8 & 2 & 9 \\
\hline 38 & 7 & 10 & 9 & 8 & 2 & 7 & 0 & 3 \\
\hline 39 & 9 & 8 & 6 & 7 & 2 & 4 & 0 & 1 \\
\hline 40 & 9 & 8 & 9 & 9 & 7 & 6 & 4 & 7 \\
\hline 41 & 6 & 9 & 1 & 9 & 0 & 0 & 0 & 0 \\
\hline 42 & 10 & 10 & 7 & 9 & 4 & 4 & 3 & 5 \\
\hline 43 & 8 & 10 & 7 & 6 & 9 & 6 & 2 & 3 \\
\hline 44 & 8 & 8 & 8 & 8 & 1 & 1 & 2 & 6 \\
\hline 45 & 6 & 6 & 7 & 9 & 2 & 5 & 0 & 7 \\
\hline 46 & 6 & 10 & 7 & 9 & 7 & 8 & 6 & 7 \\
\hline 47 & 2 & 9 & 0 & 6 & 0 & 3 & 0 & 3 \\
\hline 48 & 10 & 10 & 9 & 10 & 5 & 6 & 1 & 2 \\
\hline Total & 313 & 348 & 250 & 339 & 188 & 229 & 84 & 205 \\
\hline
\end{tabular}

A. fatua and $A$. ludoviciana plants exhibited marked genotype by environment interaction. The observed effects of the light and temperature regimes corresponded to the generally accepted view that $A$. ludoviciana germinates in the early part of the winter because it can germinate at low temperatures. Moreover, there is no necessity to overcome the effects of the husk either by rotting or exposure of the seeds to light. A. fatua was capable of germinating 

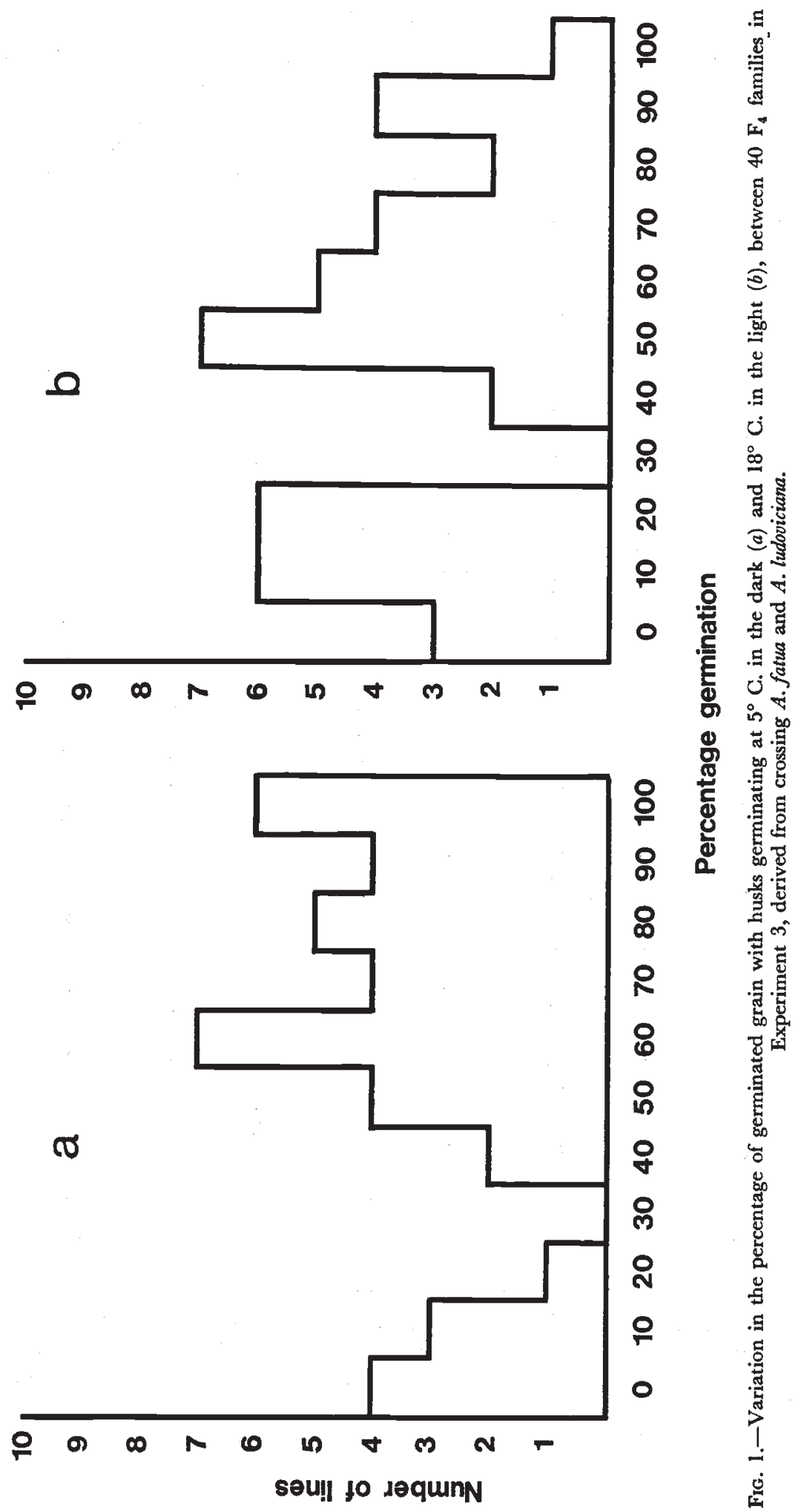
at low temperatures only after removal of the husk effect. This species, therefore, tends to germinate in spring. It is reasonable to assume that the distinctive behaviour patterns for both species have arisen as a result of selection for germination in the favourable conditions of autumn or spring. Such selection, however, cannot be assumed to have occurred either recently or in this country. Thurston (1954) found that $A$. fatua was found in England in all wheat- and barley-growing areas whereas $A$. ludoviciana was restricted to an 80-mile radius of Oxford, chiefly on heavy lands. A. fatua has been growing in Britain since early times but $A$. ludoviciana was probably introduced from France in contaminated grain during the 1914-1918 War.

The $\mathrm{F}_{4}$ families generated by crossing showed a range of variation not only between the parental types but included many lines with improved germination. Presumably the patterns of germination shown by certain of the families would be representative of the " unfit" genotypes eliminated by disruptive selection from natural populations. It is quite clear, however, that no physiological barriers to crossing have arisen between the species.

Genetic analyses of the pattern of germination behaviour may be made using the results from those treatments in Experiment 3 which gave the biggest difference in behaviour between $A$. fatua and $A$. ludoviciana. The treatments selected were in light with husks $\left(18^{\circ} \mathrm{C}\right.$.) and in darkness with husks $\left(5^{\circ} \mathrm{C}\right.$.). Two independent recessive genes might be postulated for dormancy at high temperature as in $A$. ludoviciana $(a a)$ and dormancy in the presence of the husk as in $A$. fatua $(b b)$. Assuming random assortment and selffertilisation this hypothesis leads to the conclusion that the $\mathrm{F}_{4}$ should largely consist of four homozygous genotypes of approximately equal numbers, namely $A A B B, A A b b, a a B B$ and $a a b b$. The first class would be expected to germinate well at either $18^{\circ} \mathrm{C}$. or $5^{\circ} \mathrm{C}$., the last class badly in either environment and the other classes well at either $18^{\circ} \mathrm{C}$. or $5^{\circ} \mathrm{C}$. The results from plotting the percentage germination at $5^{\circ} \mathrm{C}$. (mean of Experiments 3 and 4 ) against percentage germination at $18^{\circ} \mathrm{C}$. (fig. 2) shows discontinuity in the distribution of results but an absence of results similar to $A$. fatua $(A A b b)$. A modified hypothesis produces expectations more in keeping with the data. This proposition is that as before a single gene $(a a)$ determines the reaction of $A$. ludoviciana to high temperature. In the $\mathrm{F}_{4}$ approximately equal numbers of families of $a a$ and $A A$ type should occur. Residual heterozygosity would favour good germination. In fact, 15 out of 40 germinated poorly at $18^{\circ} \mathrm{C}$. and this is in agreement with expectation $\left(\chi_{[1]}^{2}=2 \cdot 5, P=0 \cdot 2 \cdot 0 \cdot 1\right)$. It is further postulated that the maternal husk effect at $5^{\circ} \mathrm{C}$. is controlled by three loci (B, C, D) with $A$. fatua as the triple recessive. Thus, in the $\mathrm{F}_{4}$ $\left(\mathrm{F}_{3}\right.$ maternal generation), eight genotypes are expected, only one of which ( $b b c c d d)$ would germinate like $A$. fatua. On this basis only two poorly germinating lines are expected at $5^{\circ} \mathrm{C}$. and these would be equally divided into good or bad germinators at $18^{\circ} \mathrm{C}$. In fact, three poor lines were recognised at $5^{\circ} \mathrm{C}$. but these all germinated badly at $18^{\circ} \mathrm{C}$. (fig. 2). On this hypothesis the absence of the $A$. fatua types could have occurred by chance.

The importance of the above results lies in the demonstration that the differences between $A$. fatua and $A$. ludoviciana can be best observed and understood only at certain light intensities and temperatures. In other regimes, such as the intermediate temperature in Experiment 1 or in studies on seeds without husks or seeds exposed to light as in Experiment 3, the differences are difficult to see and genetical interpretation impossible. The 
proposed genetic interpretation is based on the belief that the behaviour pattern of the species cannot be explained by a single physiological effect. The results at $5^{\circ} \mathrm{C}$. and $18^{\circ} \mathrm{C}$. require different explanations with different numbers of loci. That proposed for the husk effect at $5^{\circ} \mathrm{C}$. resembles that

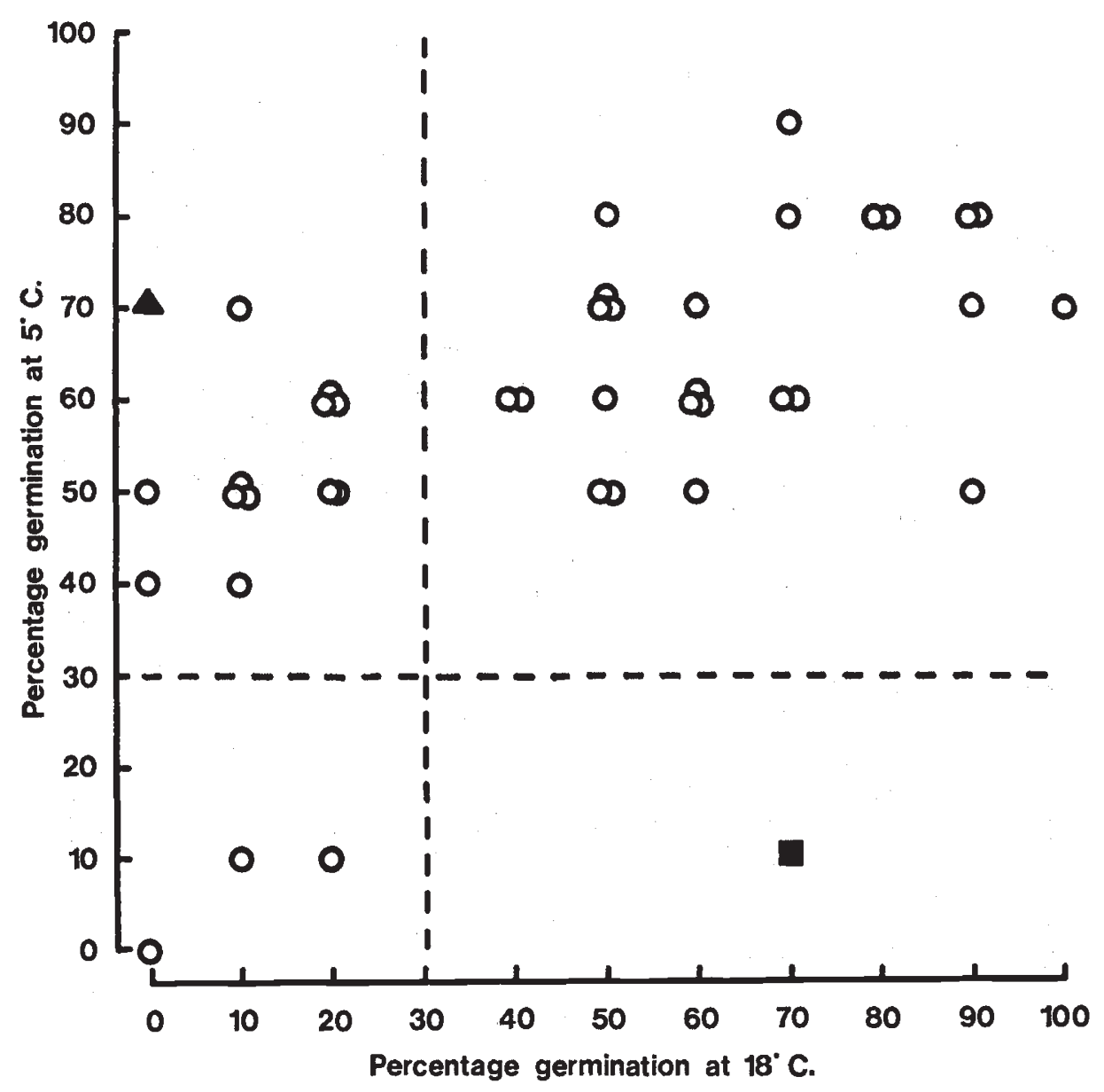

Frg. 2.-Variation within $A$. fatua $\square$, A. ludoviciana $\Delta$, and $40 \mathrm{~F}_{4}$ families $O$, for the percentage number of grains with husks germinating at $5^{\circ} \mathrm{C}$. in the dark and at $18^{\circ} \mathrm{C}$. in the light. The results at $5^{\circ} \mathrm{C}$. are mean values from Experiments 3 and 4. Dotted line at 30 per cent. germination indicates discontinuity in the data.

used to explain the results of germination in $A$. fatua by $A$. sativa crosses (Johnson, 1935b). Before the genetic model proposed can be accepted with confidence, further experiments must be carried out on seeds carefully raised in uniform environments and tested under those regimes which maximise the differences in germination behaviour between the parents.

\section{Summary}

1. The germination characteristics of Avena fatua, Avena ludoviciana and 48 families derived from crossing these species were studied in a range of environments. 
2. Germination was relatively good in soil at $10^{\circ} \mathrm{C}$. and this environment failed to bring out the extent of the differences between the species and families.

3. High $\left(18^{\circ} \mathrm{C}\right.$. $)$ and low $\left(5^{\circ} \mathrm{C}\right.$.) temperatures, exposure or protection from light, and the presence or absence of husks markedly affected germination behaviour.

4. A. ludoviciana and A. fatua showed contrasting behaviour, the former being sensitive to high temperature and the latter to the presence of husks and low temperature. The lines showed a range of behaviour patterns and many germinated well under both temperature environments.

5. A tentative hypothesis to explain the behaviour of the parents and lines was proposed. Poor germination of $A$. ludoviciana at $18^{\circ} \mathrm{C}$. may be due to the effect of a single recessive gene whereas poor germination of $A$. fatua at $5^{\circ} \mathrm{C}$. may be due to three further recessive loci. This hypothesis leads to expectations in reasonable agreement with the observations and forms a useful basis for further analysis.

6. The behaviour of the species and families was discussed in relation to field observations of the germination characteristics of these species.

Acknowledgments.-We are grateful to Miss J. M. Thurston for supplying initially the seeds of $A$. fatu $a$ and $A$. ludoviciana.

\section{REFERENCES}

BAtTLE, J. P., AND Whittington, w. J. 1969a. The influence of genetic and environmental factors on the germination of sugar beet seed. 7. agric. Sci. Camb., 73, 329-335.

BATTLE, J. P., AND WHITrrngton, W. J. 1969b. The relation between inhibitory substances and variability in time to germination of sugar beet clusters. 7. agric. Sci. Camb., 73, $337-346$.

BATTLE, J. P., AND Whitrington, w. J. 1970. Genetic variability in time to germination of sugar beet clusters. F. agric. Sci. Camb. (in press).

BLACK, M. 1959. Dormancy studies in seeds of Avena fatua. 1. The possible role of germination inhibitors. Can. F. Bot., 37, 393-402.

BLACK, M., AND NAYLOR, J. M. 1957. Inhibitory effects of white light on the germination of wild oats. Res. Rep. Can. Agric. National Weed Committee, Western Sect, 130.

CUMmiNG, B. G., AND HAY, J. R. 1958. Light and dormancy in wild oats (Avena fatua L.). Nature, Lond., 182, 609-610.

PIBHER, R. A., AND YATES, y. 1963. Statistical Tables for Biological, Agricultural and Medical Research. 6th Edition, Oliver and Boyd, Edinburgh.

PRIESEN, G., AND SHEBESKI, L. J. 1961. The influence of temperature on the germination of wild oat seeds. Weeds, 9, 634-638.

GARBER, R. J., AND QUISENBERRY, K. s. 1923. Delayed germination and the origin of false wild oats. F. Hered., 14, 267-274.

HARPER, J. L., AND MCNAUGHTON, I. H. 1960. The inheritance of dormancy in inter- and intraspecific hybrids of Papaver. Heredity, 15, 315-320.

HART, J. W., AND BERRIE, A. M. M. 1966. The germination of Avena fatua under different gaseous environments. Physiol. Plant., 19, 1020-1025.

Johnson, L. P. v. 1935a. General preliminary studies on the physiology of delayed germination in Avena fatua. Can. 7. Res., 13, 283-300.

Johnson, L. P. v. 1935b. The inheritance of delayed germination of hybrids of Avena fatua and Avena sativa. Can. F. Res., 13, 367-387.

KOMMEDAHL, T., DEVAY, J. E., AND CHRISTENSEN, C. M. 1958. Factors affecting dormancy and seedling development in wild oats. Weeds, $6,12-18$.

SEXsmith, J. J. 1967. Varietal differences in seed dormancy of wild oats. Weeds, 15, 252-255. THURSTON, J. M. 1951. Some experiments and field observations on the germination of wild oat ( $A$. fatua and A. ludoviciana) seeds in soil and the emergence of seedlings. Ann. appl. Biol., 38, 812-832. 
THURston, J. M. 1954. A survey of wild oats (A. fatua and A. ludoviciana) in England and Wales in 1951. Ann. appl. Biol., 41, 619-636.

THURston, J. M. 1963a. Weed studies. Wild oats. Rep. Rothamsted Exp. Sta. for 1962, 93-94. THURston, J. M. 1963b. Biology and control of wild oats. Rep. Rothamsted Exp. Sta. for 1962, 236-253.

THURSTON, J. M. 1964. Wild oats. Effect of photoperiod on germination. Rep. Rothamsted Exp. Sta. for 1963, 91.

rhURston, J. M. 1966. Wild oats ( $A$. fatua and $A$. ludoviciana). Effect of temperature on dormancy of seeds. Rep. Rothamsted Exp. Sta. for 1965, 102.

TOOLE, E. H., AND COFPMAN, P. A. 1940. Variations in the dormancy of seeds of the wild oat, Avena fatua. 3. Am. Soc. Agron., 32, 631-638.

\title{
CYTOGENETIC STUDIES OF A CHLOROPHYLL MUTANT OF HEXAPLOID WHEAT
}

\author{
RONA PETTIGREW and C. J. DRISCOLL \\ School of Botany, University of New South Wales, Kensington, \\ N.S.W., Australia
}

Received 6.v.70

\section{INTRODUCTION}

ChLOROPHYLl mutants of polyploids are particularly useful for the study of the interaction of duplicated genetic material. In a polyploid species in which aneuploid stocks are available, such as hexaploid wheat, the similarities and differences of loci related to the mutant locus can be examined with the aim of determining what diversification has taken place among homoeologous loci.

This paper reports on such a study of a spontaneous chlorophyll mutant recently described by Pettigrew, Driscoll and Rienits (1969).

\section{Materials and methods}

The yellow mutant of Triticum aestivum L. emend Thell. arose as a spontaneous change at one locus. The mutant form is partially dominant to normal as heterozygotes are yellow-green and homozygous mutant individuals are distinctly yellow. The mutant gene actively supresses chlorophyll formation-it is not merely a deletion since all nullisomics of hexaploid wheat are the normal green colour.

The homozygous mutant is quite vigorous and fully fertile under glasshouse conditions despite its marked deficiency in leaf pigments (Pettigrew, Driscoll and Rienits, loc. cit.). Gametes bearing this mutant allele compete equally well with gametes bearing the normal allele.

The specific chromosome location of the mutant gene was determined by the method of monosomic analysis (Sears, 1953) using the Chinese Spring monosomic lines provided by Dr E. R. Sears, University of Missouri. The conventional monosomic lines were used for 19 of the 21 chromosomes and monoisosomic (long arm) 5D and monoisosomic (short arm) monotelosomic (short arm) 7D for the remaining two chromosomes (conventional monosomics of these last two chromosomes were not on hand at the time of crossing). 